\title{
NEURAL CORRELATES OF CONSCIOUSNESS AND RELATED DISORDERS: FROM PHENOTYPIC DESCRIPTORS OF BEHAVIORAL AND RELATIVE CONSCIOUSNESS TO CORTICO-SUBCORTICAL CIRCUITRY
}

\section{CORRÉLATS NEURONAUX DE LA CONSCIENCE ET DES TROUBLES LIÉS : DES DESCRIPTEURS PHÉNOTYPIQUES DE LA CONSCIENCE COMPORTEMENTALE ET RELATIVE À LA CIRCUITERIE CORTICO-SOUS- CORTICALE}

Jean-Jacques Lemaire (1,2,@), Bénédicte Pontier (1,2), Rémi Chaix (1), Youssef El Ouadih (1), Toufic Khalil (1,2), Denis Sinardet (1), Viorel Achim (1), Adina Postelnicu (1), Jérôme Coste $(1,2)$, Véronique Germain (1,2), Catherine Sarret (2), Anna Sontheimer (1,2).

(1) Service de Neurochirurgie, CHU Clermont-Ferrand, Clermont-Ferrand, France.

(2) Institut Pascal, Université Clermont Auvergne CNRS SIGMA, Clermont-Ferrand, France.

Corresponding author: Jean-Jacques Lemaire, Service de Neurochirurgie, Hôpital Gabriel Montpied, CHU de Clermont-Ferrand, 58 Rue Montalembert, Clermont-Ferrand. France / jilemaire@chu-clermontferrand.fr.

doi: 10.1016/j.neuchi.2021.05.003.

Keywords: consciousness, disorders of consciousness, fMRI, default mode network, behavior. 


\section{RÉSUMÉ}

Nous rapportons une revue des aspects médicaux de la conscience. La dimension comportementale, des descripteurs phénotypiques, la conscience relative et les corrélats neuronaux de la conscience et de ses troubles ont été abordés successivement selon une approche holistique et chronologique.

La conscience est relative, spécifique à chacun, dans le temps et l'espace. Historiquement définie comme la perception de soi et de l'environnement, elle ne peut être séparée des comportements, ce qui implique la notion de comportements conscients avec des aspects métapraxiques et métagnosiques.

L'observation de comportements spontanés ou provoqués permet de définir trois types de troubles de la conscience, le coma, l'état végétatif ou éveillé non-répondant, et l'état de conscience minimale ou pauci-relationnel. Des techniques modernes d'exploration fonctionnelle, comme l'imagerie, améliorent la compréhension de la conscience et de ses troubles. Le fait que la conscience soit une fonction supérieure et/ou une fonction instrumentale est discuté. Les corrélats neuronaux peuvent se subdiviser selon deux voies de l'éveil, la voie supérieure cholinergique thalamique et la voie inférieure extra-thalamique, et en une circuiterie cortico-sous-corticale. Les structures du cerveau profond sont celles décrites dans les boucles, bien connues, sensorimotrices, associatives et limbiques, comme illustré dans le modèle mésolimbique des troubles de la conscience. Les cortex peuvent être distingués selon leur appartenance à plusieurs réseaux se chevauchant : (1) un réseau global incluant des boucles thalamo-corticales ; (2) le réseau du mode par défaut et les réseaux intrinsèques liés, soit le central exécutif, le réseau par défaut médial et la saillance; (3) un triple model de réseau avec le système fronto-pariétal de contrôle et ses sous réseaux dorsal et ventral attentionnels, le réseau fronto-pariétal exécutif de contrôle et le réseau cingulo-operculaire de saillance ; (4) les cortex internes et externes, respectivement médiaux tournés vers le soi, et latéraux tournés vers l'environnement. La dynamique des réseaux est le reflet de la conscience, notamment les anticorrélations comme la baisse d'activité de la région cingulaire postérieure et de celle précunéale durant les tâches attentionnelles. Grâce aux avancées récentes sur la physiopathologie des troubles de la conscience, de futurs progrès thérapeutiques significatifs, adaptés au contexte sociétal, sont espérés. Ceci dépend notamment de la divulgation de la connaissance médicale et de son transfert au grand public. 


\begin{abstract}
We report a review of medical aspects of the consciousness. The behavioral dimension, phenotypic descriptors, relative consciousness and neural correlates of consciousness and related disorders were addressed successively in a holistic and chronological approach. Consciousness is relative, specific to each individual across time and space. Historically defined as the perception of the self and the environment, it cannot be separated from behaviors, entailing an idea of conscious behavior with metapractic and metagnostic aspects. Observation of spontaneous and evoked overt behavior distinguishes three main types of disorder of consciousness (DoC): coma, vegetative state or unresponsive wakefulness, and minimally conscious or relationally impoverished state. Modern functional exploration techniques, such as imaging, increase the understanding of DoCs and consciousness. Whether consciousness is a superior function and/or an instrumental function is discussed. Neural correlates can be subdivided into two wakefulness pathways (superior thalamic cholinergic and inferior extrathalamic), and cortico-subcortical circuitry. The deep brain structures are those described in the well-known sensorimotor, associative and limbic loops, as illustrated in the mesolimbic model of DoC. The cortices can be segregated into several overlapping networks:

(1) a global workspace including thalamo-cortical loops; (2) the default mode network (DMN) and related intrinsic connectivity networks (i.e., central executive, medial DMN and salience networks); (3) a 3-fold network comprising the fronto-parietal control system and its dorsal and ventral attentional sub-networks, the fronto-parietal executive control network, and the cinguloopercular salience network; (4) the internal and external cortices, respectively medial, turned toward the self, and lateral, turned toward the environment. The network dynamics is the reflection of consciousness, notably anticorrelations such as the decrease in activity of the posterior cingulateprecuneus regions during attentional tasks. Thanks to recent advances in DoC pathophysiology, further significative therapeutic progress is expected, taking into account the societal context. This depends notably on the dissemination of medical knowledge and its transfer to a wider public.
\end{abstract}




\section{INTRODUCTION}

We assume that we are conscious, merely as a very rough attempt as the concept stems from humankind, and despite the fact that it raises questions [1]. Meta aspects of consciousness related to religion and advanced physics (e.g. brane theory) were not deemed. We also esteem that we are conscious of a part of the universe which includes our own internal universe or self. This implies the relativity of consciousness, being aware of or knowing, basic to cosmological dimensions, whether acquired or possibly innate. Basically, we focus on the medical implications of related disorders of consciousness (DOCs). Does it matter? It is an issue per se, which has not been developed. In any event, this objective is tackled by way of a condensed review starting from the behavioral dimension of consciousness, then phenotypic descriptors of consciousness followed by the relativistic dimension of consciousness, and finally the underlying cortico-subcortical circuitry. Our Ariane's thread was the acceptance that new treatments and practices will emerge from better knowledge, while being aware that this approach brings into play ethical, philosophical and societal dimensions, as recently illustrated by the case of Mr. Vincent Lambert [2].

Nevertheless, we do not discuss the quality of life in the context of severe DOCs, inferred by relatives and direct care givers, as well as by individuals and groups indirectly through the media, and possibly by the patient. This issue under debate is all the more complex as we currently have very limited understanding of what dysfunctional consciousness is, notably concerning the quality and quantity of content and access of and to consciousness, from the patient's point of view.

Definitively, we have a certain will of rationality, " $\cdots$ a conviction, akin to religious feeling, of the rationality or intelligibility of the world lies behind all scientific work ..." (Einstein, 1927, On the Scientific truth; in [3]), for better patient care.

\section{THE BEHAVIORAL DIMENSION OF CONSCIOUSNESS}

There is no consciousness without behavior, and conversely, assuming that cognition is a prerequisite. This captures the behavioral dimension of the consciousness. De facto the consciousness was always implicitly related to behavior, as it was linked to experiencing and reportability of content (see hereafter; see also e.g. [4]. We must assume that spontaneous unanticipated reflexive and instinctive aspects are part of non-cognitive, unconscious features, akin to unsupervised loops, which are out of our scope (figure 1). However, some of these features can reach the level of consciousness with the development of purposeful behaviors (see below).

Consciousness, which has obviously not yet been fully elucidated, is processed by the cortices and deep brain structures, fed by internal and external stimuli, and generates overt and covert purposeful behaviors. Perception of the self and environment, which classically defines consciousness, particularly in medicine, is a behavior. On the other hand, we must accept that the distinction between cognitive behaviors and pure reflexes or unconscious actions sometimes leads to medical questions and that the existence of a continuum is an acceptable interim hypothesis. 


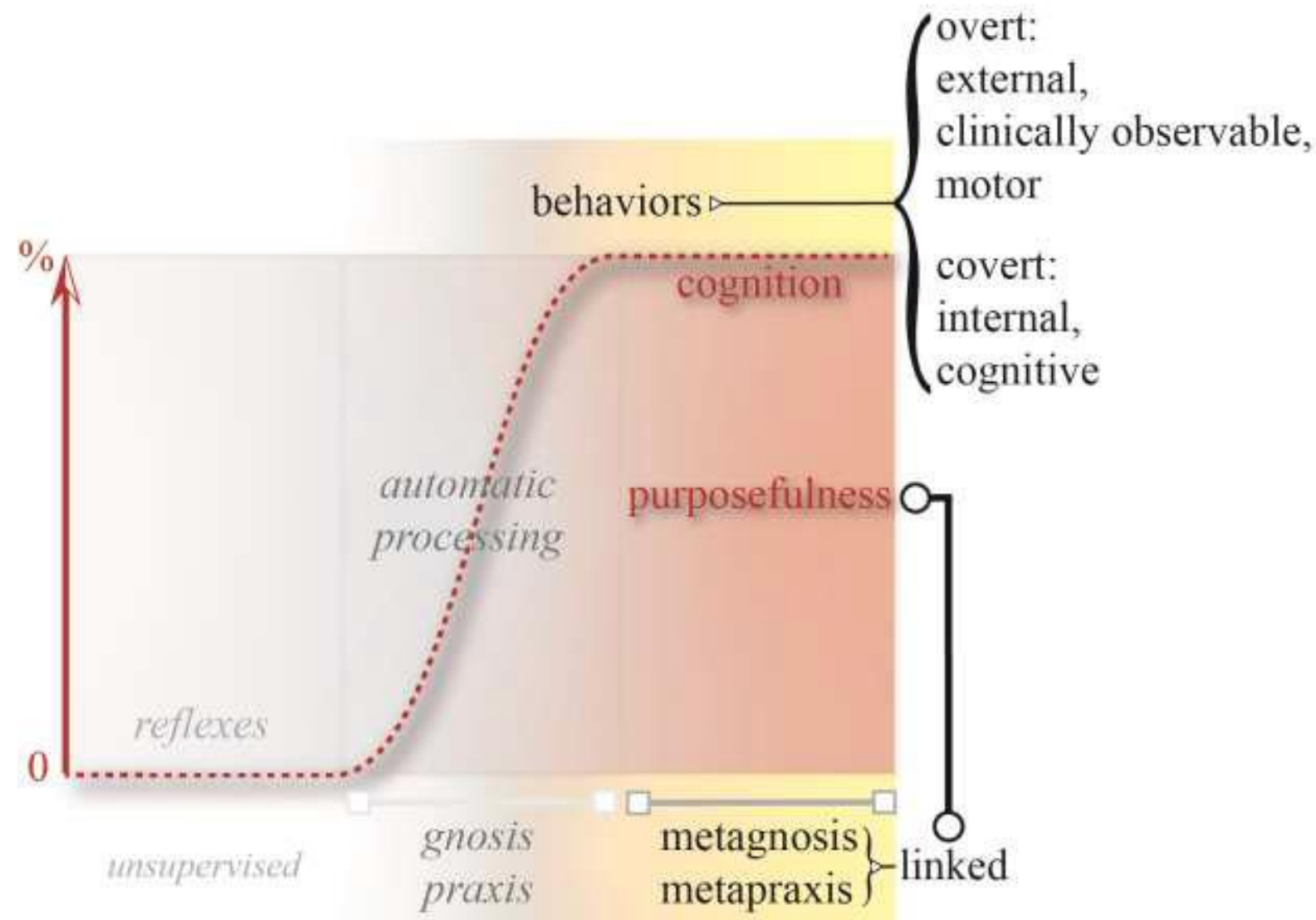

Figure 1: Phenotypic descriptors of consciousness (shades of orange), from left (no consciousness; 0\%) to right (full consciousness, 100\%). Consciousness is cognitive and purposeful, and observable clinically (overt) or instrumentally (covert) through behaviors. The reflexes, such as stretching or instinct, do not rely on full consciousness, they use unsupervised (not involved in cognition) loops, however some can reach consciousness and then participate in purposeful behavior. Conscious behavior uses metagnosic and metapraxic resources linked by the same purpose.

Pragmatically, genuinely conscious behaviors are behaviors that are thought or minded. The gnosis and the praxis, as medical constructs, have been established since the beginning of the 20 th century (e.g. [5]), and enable specifying two dimensions of consciousness, recognition and action, respectively. Historically, they were formulated from the observation of disturbed motor activities resulting from impaired cognitive behaviors, the agnosia and the apraxia. Therefore, the integration of praxic and gnosic dimensions of cognitive, covert activities in consciousness were at the back but benefit increasingly from the development of advanced techniques such functional magnetic resonance imaging (fMRI, see hereafter). Although the perimeters of praxis and gnosis are still not fixed (see e.g. [6-8]), and although the distinction has been called into question [5], we use them to specify dimensions of consciousness, while being aware of a certain vagueness. Gnosis refers to semantic recognition on the basis of the primary information received by the sensory and somesthetic cortices, and on internal sources of visceral origin, for example. The gnosis of thoughts should complete this description cogently, as the direct exploration of the neural correlates of thoughts has begun $[9,10]$. Praxis refers to goal-directed sequences of actions, acquired, overt, logically assembled, observable through spontaneous and provoked motor sequences. Each praxis covers a unique and limited goal, as an elementary unit or brick enabling, by assemblage, the achievement of complex tasks under full cognition. In line with the gnosis of thoughts, we assume that the praxis of thoughts will further complete 
this definition, as covert, non-clinically observable, elementary, logically assembled, purposedirected sequences of thoughts. Nevertheless, the place of gnosic and praxic processes in cognitive, covert, activity has not been determined. We propose that the metagnosic and metapraxic components of consciousness, in concomitance, are temporary concepts, working together purposefully and framing the behavioral dimension of consciousness.

Metagnosis and metapraxis are the higher levels of recognition and action, belonging to conscious behaviors and hence cognitive. They superpose gnosis and praxis, which, conversely, taking into account clinical observations of agnosia and apraxia, are unconscious as instrumental means, and observable as pieces of conscious behaviors. Attention should be interpreted as a metagnosic behavior, which can be directed internally or externally. When attention is focused or goal-directed, it is part of a top-down process that awaits an item of information such as visual or auditive or visceral; it is a typical conscious behavior. When the mind is wandering internally (see the default mode network below) or externally (looking at clouds or listening to relaxing sounds) attention is not goal-directed, it is blurred. However, physiologically this wandering-mind state is voluntary and belongs to conscious behaviors. Any salient events can prompt conscious behaviors, such as sensorial triggers (see the attentional cortices below), and quite likely, thoughts. Consequently, physiologically, conscious behaviors are on the top, switching attention between focus and unfocused states. Language belongs to conscious behaviors and enables, among other things, spreading and manipulating knowledge, besides intra and inter individual interactions. From clinical studies we have learned that hemispheric language specialization or dominance is leftward lateralized, as is the well-known Gerstmann's syndrome observed following left parietal posterior lesions that mix agnosia and apraxia features. However, instead of a global hemispheric dominance suggested from historical studies, each hemisphere, cortices and basal ganglia, could play a specific role in different praxic aspects $[8,11]$, such as vestibular controls under the supervision of right parietal and thalamic regions $[12,13]$.

\section{PHENOTYPIC DESCRIPTORS}

In the general population, consciousness refers to the state of being aware or conscious, an intuitive or reflexive knowledge, the fact of being responsive, of perceiving, of itself and the world, and a higher level of mental life [14-16]. The Latin roots of the word [17] point to a dual conception of (1) knowledge-awareness, of self, and sharing with others; and (2) of guilt and judgement. These aspects are mostly metagnosic, metapraxic, and cognitive. The perceptive dimension of known information either external or internal, also points to the notion of unknown information (see below). The judgment of behaviors, as illustrated by Hugo [18] with the symbolic representation of guilty consciousness by an eye " $L$ ' oeil était dans la tombe et regardait Caïn" (The eye was in the tomb and looked at Cain), and mental life such as mind training [19], is outside the scope of this article.

Starting with Plum and Posner [20], the role of the cortex and subcortical activating systems, such as those of the brainstem and thalamus regions, was identified. Considering that the human brain is above all a behavior machine (see hereinabove), overt behaviors are manifest and detectable on the ground, whereas covert behaviors, if there is no movement or language, are objectively accessible only through functional explorations, such as fMRI protocols performed at rest or during tasks. At the bedside, consciousness was defined notably as the perception of the self and the environment [20]. The self includes the thoughts illustrated by "Cogito, ergo sum" (I think therefore I am) of Descartes [21], and the environment in its wide meaning which includes others.

It is noticeable, as shown by the "Cogito, ergo sum", that cognitive, metagnosic and metapraxic aspects are present, through covert perception and recognition (of thought), and covert (cognitive; an inference) and overt (language; writing) behaviors. 
Thus, the medical definition of consciousness is restrictive, almost exclusively perceptionmetagnosis oriented. Whatever the case, the medical perception of the self and the environment, supported by biological phenomena, is merely an extension of the general historical definitions.

This is probably due to the fact that the focus then was essentially on wakefulness, with related behaviors remaining in the background. Yet, intuitively and objectively, as already mentioned, behaviors are systematically associated with awareness. Conscious behaviors are, however, not always easy to define at the bedside, particularly in the case of limited or inconsistent communication (see DOC hereinafter). Behaviors are often qualified as voluntary, meaning that the subject wants to display them purposefully, but the purpose is not always obvious to the observer. For instance, if the observed subjects cannot explain their behavior by any means, or if they suffer from confusion of whatever cause, the observer can miss the purpose. This is dramatic for locked-in patients if no diagnosis of preserved consciousness is made. The difference between voluntary and involuntary behaviors or actions is also more subtle when intention and necessity are taken into account in parallel with philosophical considerations [22]. Interestingly, adjectives such as conscious or unconscious or voluntary and involuntary, are used indifferently to describe behaviors and stimuli. So, the number of combinations of adjectiveword that describe the circumstances where consciousness is considered increases dramatically, sometimes leading to awkwardness. For instance, the perception of a spontaneous automatic neurovegetative involuntary acceleration of the heartbeat, e.g. following an involuntary arrhythmia or a voluntary movement or an instinctive fear, can generate a covert or overt conscious behavior, such as mental stress or alertness with reflexive neurovegetative modifications. This is particularly true in this case if the subject is aware of a personal cardiovascular disease. The second example comes from epilepsy, where spontaneous, involuntary, non-conscious neuronal discharges, trigger a loss of consciousness or consciousness-like behaviors qualified as automatic, with emotional dimensions, at least from the observer's viewpoint. The third example is the condition of subliminal stimuli and conscious behaviors. They have been described experimentally, and hence not truly spontaneous, but the authors [23] showed that conscious behaviors can react to so-called subliminal or preconscious stimuli, under the modulation of attention.

In the current perceptive clinical understanding of consciousness, the behaviors observed cover a wide range of situations, from simple, often qualified as reflex or automatic behaviors, to sophisticated, such as so-called executive or cognitive behaviors. The words, "reflex", "automatic" and "involuntary" are often used indifferently. That being so, roughly speaking, automatic behaviors should use little cognition, if any at all, and cognitive behaviors belong to superior or higher functions or high cognition, also referred to as intelligence, either overt or covert. The superior or higher brain functions cover a wide range of concepts in neurology, psychology and sociology [24]. In contemporary neurology and neuropsychology, studied at the university and in the hospital, the so-called superior functions cover language, praxis and gnosis, and cognitivebehavioral dimensions, such as the executive and intellectual functions and memory (see e.g. [25]).

Language, praxis and gnosis are, in this case, often called instrumental functions, considered as means enabling cognition. Interestingly, in this case, the related dysfunctions, aphasia, agnosia and apraxia, could be interpreted as consciousness disorders, as the patient can be unaware of certain aspects of the self and the environment, because of neglect or misunderstanding. Thus, whether consciousness should be understood as a global phenomenon, or specialized consciousnesses, such as knowledge - awareness of different parts of space or the body or mind resources, or as different functions such as language, dressing and walking, has not been settled. In the general population, cognition refers to the acquisition of knowledge and understanding through thought, experience, and the senses, and intellectual activity, which may be empirical 
[14-16]. The Latin roots illustrate the notions of knowledge and instruction (of something, an investigation) [17].

Several theories describe different aspects of consciousness (see e.g. [26]), including the neural approach whose aim is to decipher the neural correlates. In parallel, the cognitive nature of consciousness is always a subject of debate in psychology [27]. Nevertheless, the so-called "hard problem" [28], i.e. how the brain generates a conscious experience, remains. From the above objectives the hard problem can be raised to the same level as cognition and related concepts.

Experience refers to perception and thought, engaging cognition, which includes phenomenological consciousness related to the senses and immediate experience. A developmental and evolutionary approach inferred two aspects of consciousness [29,30]: anoetic consciousness, receptiveness or perceptual, primitive, or unknowing consciousness; the noetic and autonoetic, knowing consciousnesses, of a higher level, where noetic consciousness classifies information and autonoetic consciousness relates to the recall of autobiographical memories and one's projection of the self into the future. It is noticeable that humanconsciousness-like behaviors, which could be called experience by humans, are known in other species, such as emblematic ones in apes [31], and little-known ones in birds [32], and are most commonly encountered with pets. Each living system could have a relative consciousness (see hereinafter) according to its own experienced universe. Genuine conscious behaviors or features, mimicking conscious behaviors of humans, should not hide the difficulty of distancing ourselves from anthropocentric considerations.

Whatever the case, hierarchical considerations on the consciousnesses of living systems are outside the scope of this article. Indeed, human consciousness could be specified as that which purposefully self-examines and takes into account others, over large time periods up to a lifespan and beyond.

Beyond human consciousness could be, conceivably, the only one, if humankind is unique in the universe.

On the basis of all the above-mentioned elements, we can reasonably infer that consciousness relies on specific stimuli and cognitive-motor processes that purposefully interact with the self and the environment. This definition partially overlaps with that of autopoiesis and the cognition of systems, which together define a living system [33].

Memory takes place in the consciousness process as an internal reference library. Experimental data show that the storage is distributed in the neocortices [34] and that the prefrontal cortices are actively involved [35], whereas memory elements and ensembles are processed (in and out) within the hippocampal formation [36,37]. Memory could be prefilled by innate references and further completed by following experiences, including education and training. However, there is no evidence of such an innate brain memory library. We observe only that the temporospatial development of the brain (neurons and myelin), at least genetically and epigenetically determined, enables the implementation of consciousness. The early development over the embryonic and fetal periods, could be the support of a transition from anoetic to noetic consciousness, but this raises and exacerbates the "hard problem". Other questions are raised by the irruption of memory recalls, whether passively or actively, voluntarily or involuntarily, following conscious or unconscious physiological or pathological events, and the vague field of knowledge of feelings of persons or situations. This is especially the case since it has been shown experimentally that false memory can be created in the hippocampus [38]. This brings us to the frontiers of physiology, such as flashbacks and reviviscence, and of pathology, such as confusion, ghost limbs and hallucinations during neurologic and psychiatric diseases and syndromes, and of artificially altered states of consciousness using psychoactive drugs or cognitive approaches (e.g. [19,39]. Although all these dimensions are linked with consciousness and rely on neural support, they are outside the scope of our topic. 


\section{RELATIVE CONSCIOUSNESS AND ITS SPAN}

The relativistic aspects of consciousness englobe consciousness in line, in one way or another, with the relativistic approach of cosmology. This relative consciousness expands the acquired consciousness of the universe and the self, from individual to populational aspects, as well as beyond the experienced universe (figure 2). Practically, relative consciousness expresses both the relativity of its content and the relativity of the examination of its content according to the knowledge and cognition of the observer, who can be the self or the other. At the same time, on an individual basis, the span of relative consciousness increases from a limited, primary consciousness, assimilable with anoetic consciousness through raw processes (figure 2). This anoetic consciousness is described as unknowing consciousness [30]. It implies that we should consider an intermediate state, a pre-consciousness, enabling primary pre-consciousness behaviors without knowing, which brings us back to the notion of necessity, such as feeding. Hence relative consciousness is above all an acquired consciousness, fully operational as it reaches cognition, and which can be considered as noetic. Relative consciousness involves all consciousness related meta dimensions, metapraxis and metagnosis up to metacognition. The span of relative consciousness increases by training in all types of language, such as spoken, written, drawing and body languages, and hypothetically by genetics, and through individual and populational perspectives.

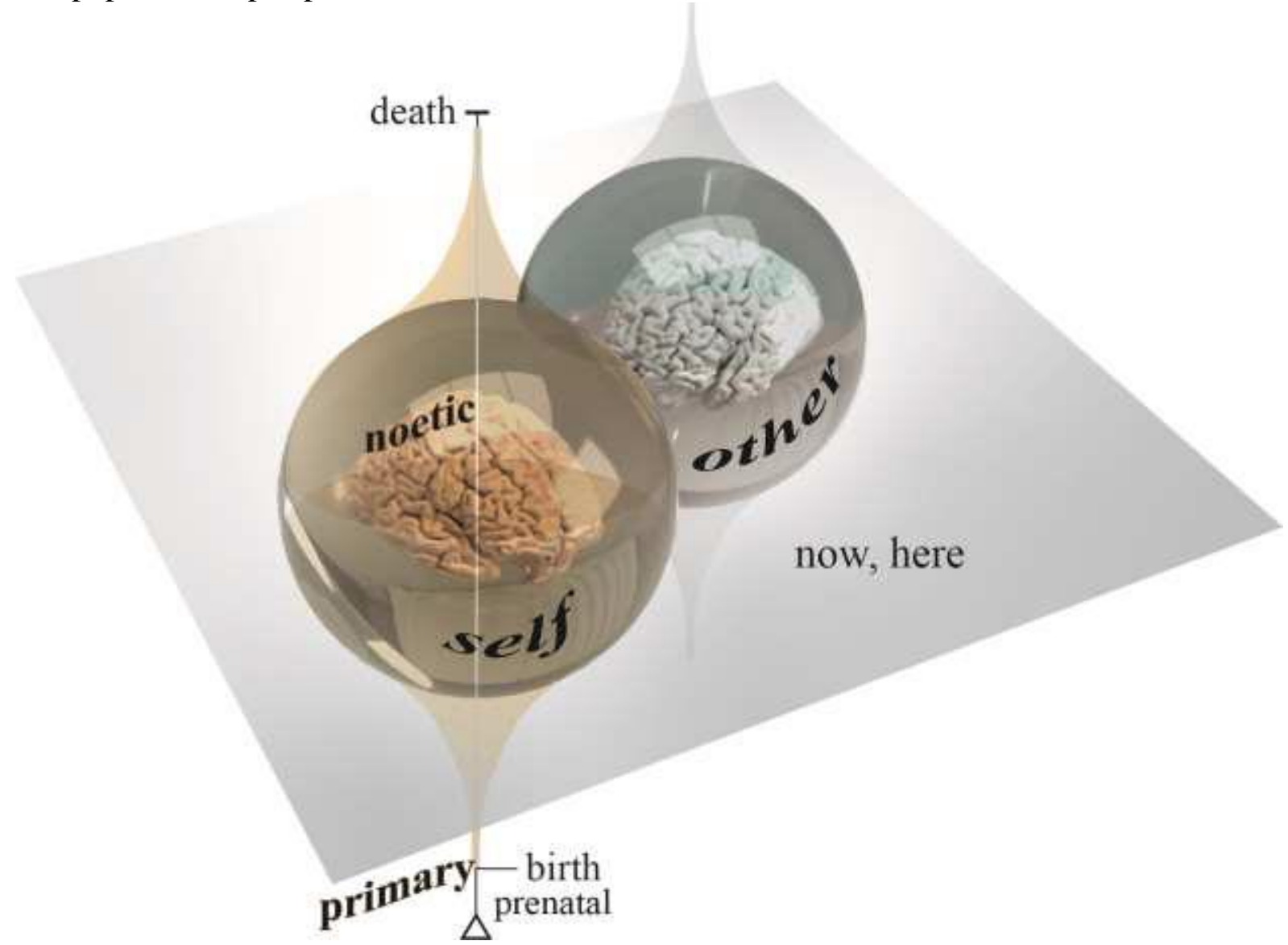

Figure 2: The relative consciousness of an individual (beige) within the extended universe (cosmological space-time) expresses the relativity of its content at a certain location and at a certain moment, accounting for before (back through the past) and after (forecast, into the future), over the life span (from birth, possibly also prenatal, to death). The span of relative consciousness reaches a maximum noetic dimension during life. It starts from a limited, primary state, with raw processes some of which could be innate. Fully operational relative consciousness relies on cognitive, purposeful, behaviors. Relative consciousness also expresses the relativity of the examination by the observer, who can be the self or the other. 


\section{NEURAL CORRELATES OF CONSCIOUSNESS AND DOC}

We report neural correlates of human consciousness from stimulus processing to different cognitive processes, from the basic level, such as alertness, to a high level, such as intellectual processes. Data obtained from studies of DOCs are included, providing indirect insights into consciousness: coma, with no signs of consciousness and no eye-opening; vegetative state (VS), also named unresponsive wakeful syndrome (UWS) [40], with eye-opening and no consciousness behavior observed; minimally conscious state (MCS) [41], with inconstantly observed consciousness behaviors; MCS + and MCS - are subcategories that depend on the complexity of observed behaviors $[42,43]$. These diagnoses are exclusively based on clinical observations, but we now know that a covert consciousness-like cerebral activity, revealed by fMRI, remains in the population of DOC patients (e.g. [44]). The mismatch between two, covert and overt, consciousness-like activities was well exemplified in covertly aware vegetative patients [45], further reported as cognitive motor dissociation [46]. However this apparent mismatch is relative to the observer point of view and to the definition of DOC, and depends on the technique of brain function analysis. For instance emotion, which facilitates overt behaviors at bedside when relatives are present, can be used to reveal covert behaviors [47]. Hence the concept of mismatch must be used very cautiously in clinics accounting the relativity of consciousness (see above), and the technical-knowledge dependence of the interpretation of clinical picture. One might suppose that historically locked-in patients could have been the very firsts with apparent cognitive motor dissociation. This raises numerous questions about the specificity and selectivity of the information collected at the bedside, and even for the information provided by older techniques such as electroencephalography (EEG) and evoked potentials. At the same time, this recent knowledge will very likely modify the classifications of DOCs, improving diagnoses, prognoses and treatments, including the cessation of treatments. Indeed, Naccache [48] recently proposed to introduce new types of evidence from EEG, fMRI and Pet-Scan, in addition to clinical examination, to classify the impairments of consciousness. Hence, we see that we move slightly away from clinical to combined instrumental-clinical diagnosis. The notion of DOC, the pathologic dimension of consciousness in medicine, requires a brief introduction to the particularity of sleep and anesthesia.

Indeed, although physiological with a circadian cycle, the example of sleep is often presented to the general public as an analogy of coma. This is also true of anesthesia, which is neither physiological nor a kind of sleep, though experimental studies of DOC have used anesthetic models as substitutes of true clinical pathophysiologic conditions, while exploring the mechanisms of anesthesia [49]. The overt status of sleep and anesthesia illustrates the impact of observing the closing of eyes by relatives, who are often confused by the fact that the eyes are always closed in comatose patients, whereas they open, cyclically when waking up in normal life, or systematically after general anesthesia. Indeed, if a DOC patient opens their eyes it does not mean that the patient has woken up or recovered consciousness, but merely that certain brain functions restart, following a complex process of functional and structural reorganizations. The spontaneous dynamics of recovery from coma to VS and to MCS, and then the evolution toward disability or full recovery, dramatically complexifies the general public's understanding of DOC, especially since the average timeline of spontaneous progression is not always clearly discussed with the patient's relatives, and depends on the specific clinical context. Nowadays, the following terms should be recommended [43]: (1) prolonged - continuing DOC if the clinical state lasts more than one month; (2) chronic, after 3 months following anoxic or metabolic injury, and after 12 months following trauma for more severe patients, i.e. VS and MCS-, besides which 6 additional months must be added for less severe cases or MCS+; (3) permanent after 6 months of stable chronic conditions assessed regularly. Frequent DOC clinical pictures, following stroke and tumor-related (lesion and treatment) brain injury, are neglected and fall in-between anoxic-metabolic and traumatic 
conditions. They are also three other very common clinical pictures of DOC in addition to the DOCs described above, in the absence of psychiatric symptoms that could lead to biases: spatial or temporal disorientation; obnubilation (no reaction in this context, but "cloudy" or "obscure" in the literature); confusion, a dreamlike experience often associated with fluctuations of attention and vigilance (transitory spontaneous eye-closing). Obnubilation could be interpreted as a transitory lockdown of the attentional state often accompanied by an interruption of actions, notably mutism, such as that observed following concussion.

As mentioned above, the modern medical dimension of consciousness was first considered through the prism of wakefulness, and at the bedside the absence of wakefulness was named coma (from Greek, " $\kappa \hat{\omega} \mu \alpha$ ", meaning deep, prolonged sleep [50]). Wakefulness is controlled by two main routes that originate within the brainstem, in the ascending reticular activation system, whose electric stimulation effects were described as early as 1949 by Moruzzi and Magoun [51]. The dorsal route or superior thalamic cholinergic pathway reaches the thalamus, and the ventral route or inferior serotoninergic-noradrenergic basal-forebrain pathway, or extra thalamic pathway, reaches the hypothalamus and forebrain (see [52] for a review). Acute lesions, either hemorrhagic or ischemic, of the upper brainstem are prone to induce DOC and particularly coma [20,53]. The electrical stimulation of the upper tegmental region, and possibly of the cuneiform nucleus in severe DOC patients has shown that frequencies of $50 \mathrm{~Hz}$ and $250 \mathrm{~Hz}$ can improve consciousness [54,55]. It has be shown that vagus nerve stimulation that modulates tegmental and thalamic activities in particular, can also improve DOC signs (e.g. [56]).

The thalamus is the emblematic deep-brain structure involved in consciousness. The nuclei have been placed in specific groups directly involved in sensory-motor activity, unspecific groups $[57,58]$, or in principal or relay (=sensorimotor), limbic (anterior, midline, and medial intralaminar nuclei) and connection nuclei groups between the relay and the limbic groups [59]. According to the calbindin and parvalbumin bindings of cells, nuclei have also been segregated into matrixcalbindin and core-parvalbumin groups, which involve the main parts of the central lateral and the parafascicular nuclei, and the centromedian and the reticular nuclei respectively $[60,61]$. The notion of central thalamus was highlighted by Schiff [62] and covers the extended central region of the thalamus centered on the intralaminar nuclei and the close neighborhood. Generally, the activation of the cortices can be explained by three mechanisms: the coincidence of the activities of specific and unspecific groups [57]; the gateway to the cortex of stimuli by the control of the reticular thalamus $[63,64]$; the arousal of the cortices by the intralaminar nuclei $[62,65,66]$. The role of midline and intralaminar nuclei has also been highlighted in the cognitive and executive functions as well as in goal-directed behaviors [67,68]. Nevertheless the precise mechanism of thalamo-cortical functionality is still unsettled [69]. Electric deep brain stimulation (DBS) of thalamic structures has shown clues and evidence of improved consciousness in severe DOC patients, either during acute low frequency [70] or chronic high and low frequency [55,71-75] conditions. The spontaneous restoration of thalamocortical metabolic connectivity also seems to be linked with recovery from UWS [76].

The role of deep gray nuclei in the consciousness process has been less explored. The striatum was suspected to participate in thalamo-tegmental controls of consciousness [57]. The claustrum and anterior insula should participate in the consciousness process through their interactions with cortices [77-80]; the anterior insula being nowadays included in the cortical structures that participate to the salience network [81] (see below). Experimental studies have shown that the modulation of pallidum activity can provoke consciousness-like activity, which is suppressed by thalamic lesions [82]. Acute 5-Hz electric stimulations of the pallidum, alone and coupled with 50-Hz reticular thalamic stimulation, provoked consciousness-like behaviors in a DOC patient [70]. 30-Hz chronic pallido-thalamic DBS provoked consciousness-like behaviors in DOC patients [73]. 
In parallel to the extensive knowledge obtained from the basal ganglia and other deep gray nuclei in neurodegenerative disorders, greater attention is being given to the implication of corticosubcortico-thalamo-cortical loops in consciousness. Whether the cortices or the deep brain are at the origin of the phenomena is still unknown, and could be vain as both are linked by the wellknown sensorimotor, limbic and associative loops (see reviews [83,84]). In this respect, the mesocircuit model was proposed to explain the different DOCs [85,86]: the downregulation of the cortex being the result of widespread lesions, either structural or functional, across corticosubcortical structures. A growing body of works has shown the implication of extra thalamic subcortical components in consciousness [87-90] and DOCs [91]. However structural lesions of deep gray nuclei do not always provoke permanent DOC [9294]. The figure 3 illustrates corticosubcortical circuits related to DOCs.

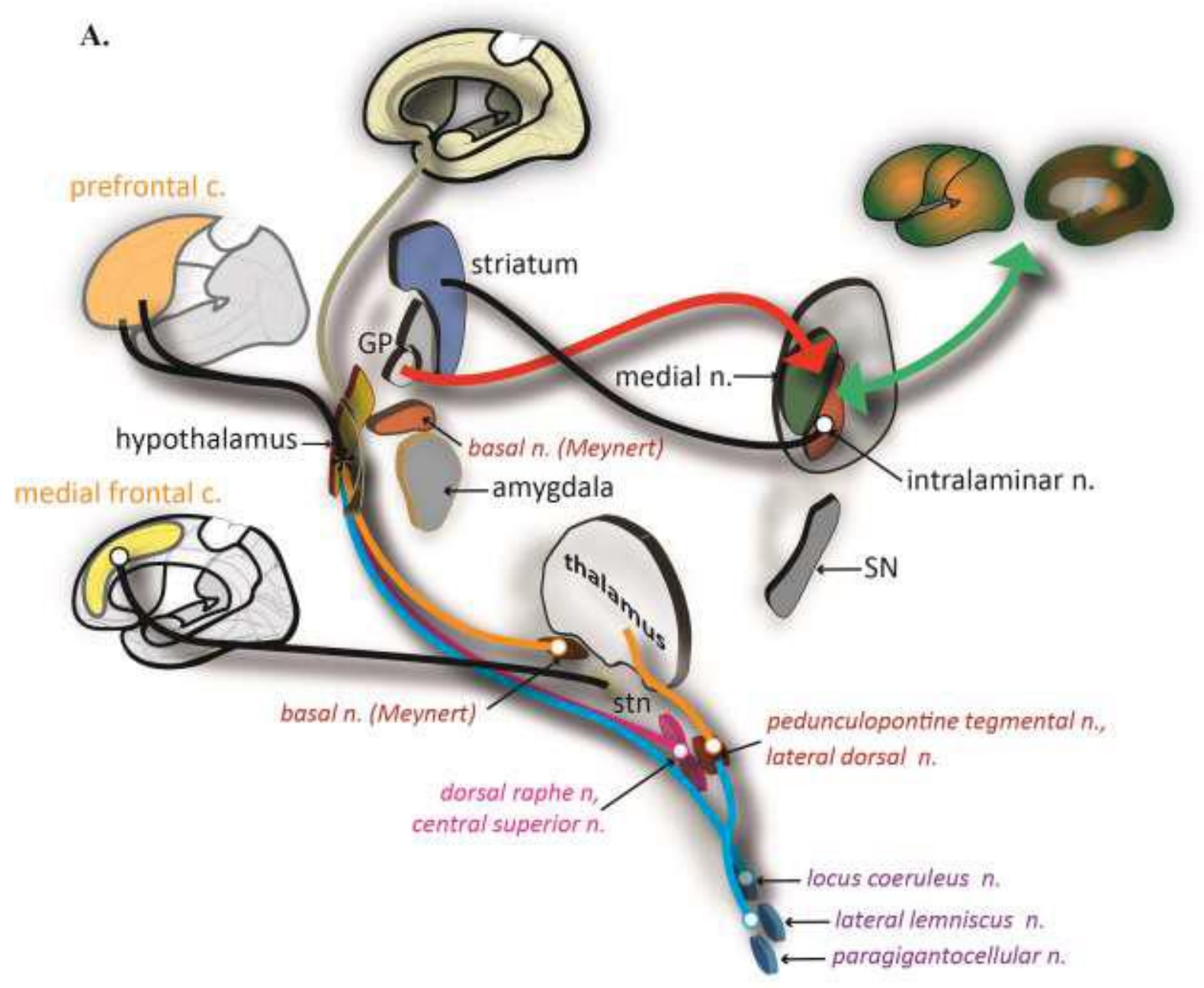




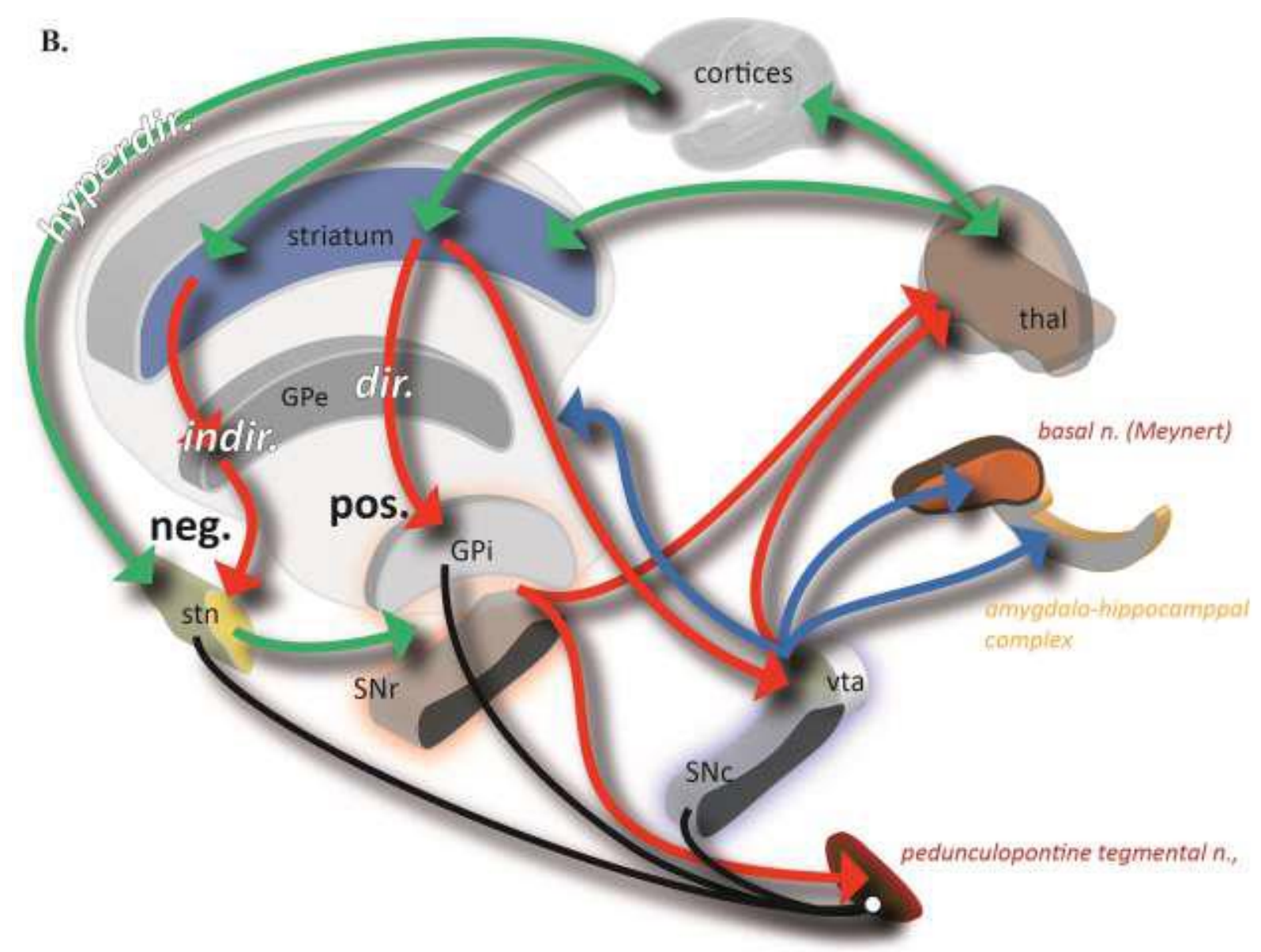

Figure 3: Cortico-subcortical circuits related to disorders of consciousness: A, structural, $B$, functional aspects; c., cortex; n., nucleus; stn, subthalamic nucleus; GP, globus pallidum, e, extern, i, intern; SN, substantia nigra, c, compacta, $r$, reticulata; hyperdir., dir. and indir., hyperdirect (prepares action or overall inhibition), direct (selected action program, disinhibition) and indirect (stop action) cortico-subcortical pathways; black line, pathway; thal, thalamus; vta, ventral tegmental area; neg., inhibits, and pos., reinforces, behaviors; acetylcholine (orange), noradrenalin (light blue), glutamate (green, activation), serotonin (pink), dopamine (dark blue) Gaba (red, inhibition) neuromodulators.

The role of the cortices in consciousness was extensively studied using electrophysiological and neuroimaging works. These pioneering integrative works proposed a model called "global workspace" including thalamo-cortical loops [4,95-98]. They proposed that long distance cortical connections particularly of the pyramidal cells of the prefrontal, cingulate, and parietal regions would allow consciousness $[4,95,97]$, in line with numerous others works (see e.g. [57,99-101]).

If undoubtedly cortices play an important role in consciousness, extreme pathological conditions such as hydranencephaly questions medicine, science and beyond [102]. In parallel, the metabolic activity of the brain at rest, i.e. when a subject experiences covert wandering thoughts, reveals local specificities notably unique high activities of the medial cortices.

This particular distribution was qualified as the Default Mode Network (DMN) defined from Pet-Scan studies $[103,104]$ and further studied with fMRI (see e.g. [105-110]). The DMN is in fact the very first, robust, physiologic brain functional network, observed in imagery, and this, even if it relies on covert activity, which is fortunately at rest and quasi-reproduceable by any human being. 
Moreover the highest metabolic rest activity of the brain is located in the posteromedial cortices, the precuneus and the posterior cingulate [111]. This special cortical region, particularly the posterior cingulate, seems to be a key structure in consciousness, DOC and cognition [112]. The characteristic of DMN is that the cortices deactivate when attention is focused during goaldirected behaviors, notably involving the external environment: the right and left, bilateral junction of the posterior cingulate - precuneus, the inferior lateral parietal lobule, and the medial prefrontal cortices; the left prefrontal cortices and the inferior temporal cortex; the right mesiotemporalamydagala region [104,113]. The activity of the DMN is markedly reduced in DOC patients [114].

Interestingly, the potentiality of recovering impaired functional connectivity between the medial prefrontal cortex and the posterior cingulate observed in DOC, could be a prognostic marker of further clinical recovery [73,115]. From the entire data of the total brain voxels constructed during an fMRI acquisition, notably at rest, the segregation of voxel activities according to temporal relationships, historically using independent component analysis, enabled to identify canonical functional networks, further named intrinsic connectivity networks (ICNs) [116]. These ICNs are the maps of the functional networks permanently active in a living brain, revealed at rest and during tasks. Three main ICNs were segregated: the central executive network (CEN), lateral, with the dorsolateral prefrontal and parietal cortices; the DMN, medial, with the ventromedial prefrontal and the posterior cingulate cortices, which could be acronymized as $\mathrm{DMN}_{\mathrm{m}}$; the salience network ( $\mathrm{SN}$ ), with the ventrolateral prefrontal, the anterior insula and the anterior cingulate cortices [116,117]. The attentional cortices, explored during visual tasks, were segregated into dorsal and ventral networks (DAN, VAN), respectively related to spatial cues and non-spatial, salience or novelty, cues $[107,108]$. Salience reflects the distinctiveness and relevance of stimuli [107]. Indeed, the DAN detects an element in space using voluntary attention, thus purposefully, and consequently was qualified as topdown attention. The VAN focuses on an item of information using "natural" spontaneous salience (e.g. brightness or size) during purposeless spatial exploration, and was qualified consequently as bottom-up attention. The DAN covers roughly the lateral pre frontal cortex (the frontal eye field, the intermediate and the inferior frontal gyri, and the inferior frontal junction), the lateral parietal cortex (including the inferior parietal lobule and the intraparietal sulcus), the lateral occipital cortex (including V3) and the posterior temporal region. The VAN covers roughly the supra marginal gyrus, the superior temporal gyrus, the inferior frontal gyrus, the insula and the inferior frontal junction; it predominates in the right hemisphere. Further fMRI studies have also enabled the identification of several other functional networks such as the largescale frontoparietal control system (FPCS; anterior insula, dorsolateral and ventrolateral prefrontal cortices, dorsal anterior cingulate, and inferior parietal lobule), the frontoparietal executive control network (FPE-CON; bilateral, lateral prefrontal cortex, dorsomedial prefrontal cortex, and inferior parietal lobule) and the cingulo-opercular salient network (COSAL; bilateral, anterior insula/frontal operculum and dorsal anterior cingulate cortex). The FPCS is coupled with both the DMN and the DAN [118,119] allowing the allocation of resources [109]. The FPE-CON is correlated with the visual cortex (the activities are considered as synchronous) linked with the lateral DAN, whereas the CO-SAL is correlated with the DMN [120]. Effective connectivity analysis, prone to identify causalities, showed the major role of the right fronto-insular cortex (ventrolateral prefrontal cortex + anterior insular cortex) of the $\mathrm{SN}$, which can switch between the $\mathrm{DMN}_{\mathrm{m}}$ and the CEN [117]. The Pet-Scan activity of deep thalamo-caudate structures and the fronto-parietal network is impaired in DOC patients [121,122], and the external stimulation of dorsolateral prefrontal cortices of patients increases signs of consciousness $[123,124]$.

The cortices were also segregated into external, i.e. turned to the perceptual awareness of the external environment, and the internal, i.e. turned to the self or stimulus independent thought 
("wandering mind"), which are anticorrelated (when one works the other stops) [125-127]. These cortical networks are summarized in figure 4.

A.
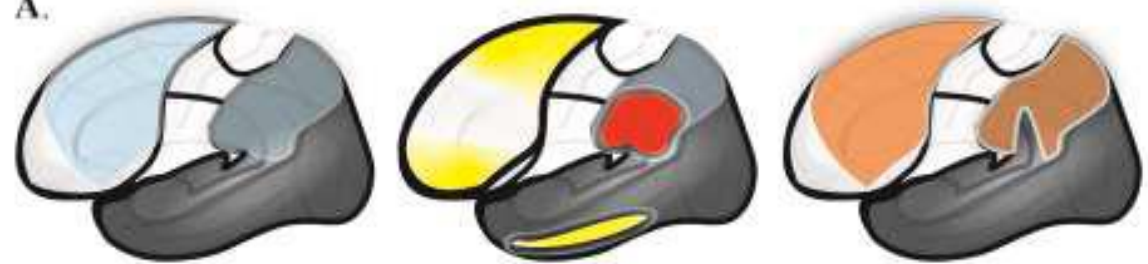

$\mathrm{DMN}$

DMN-deactivation

Global workspace
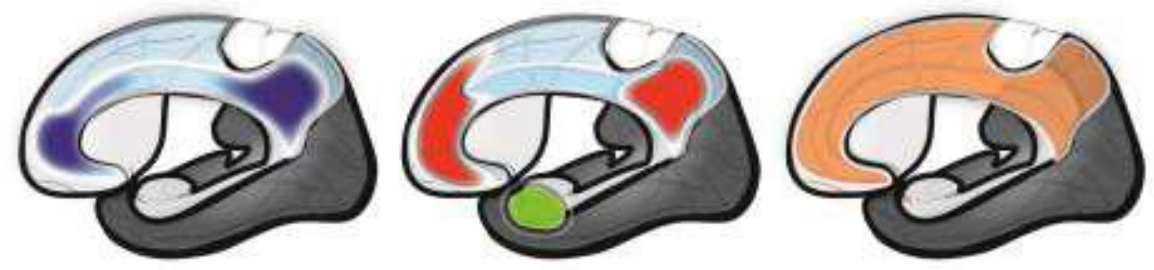

B.
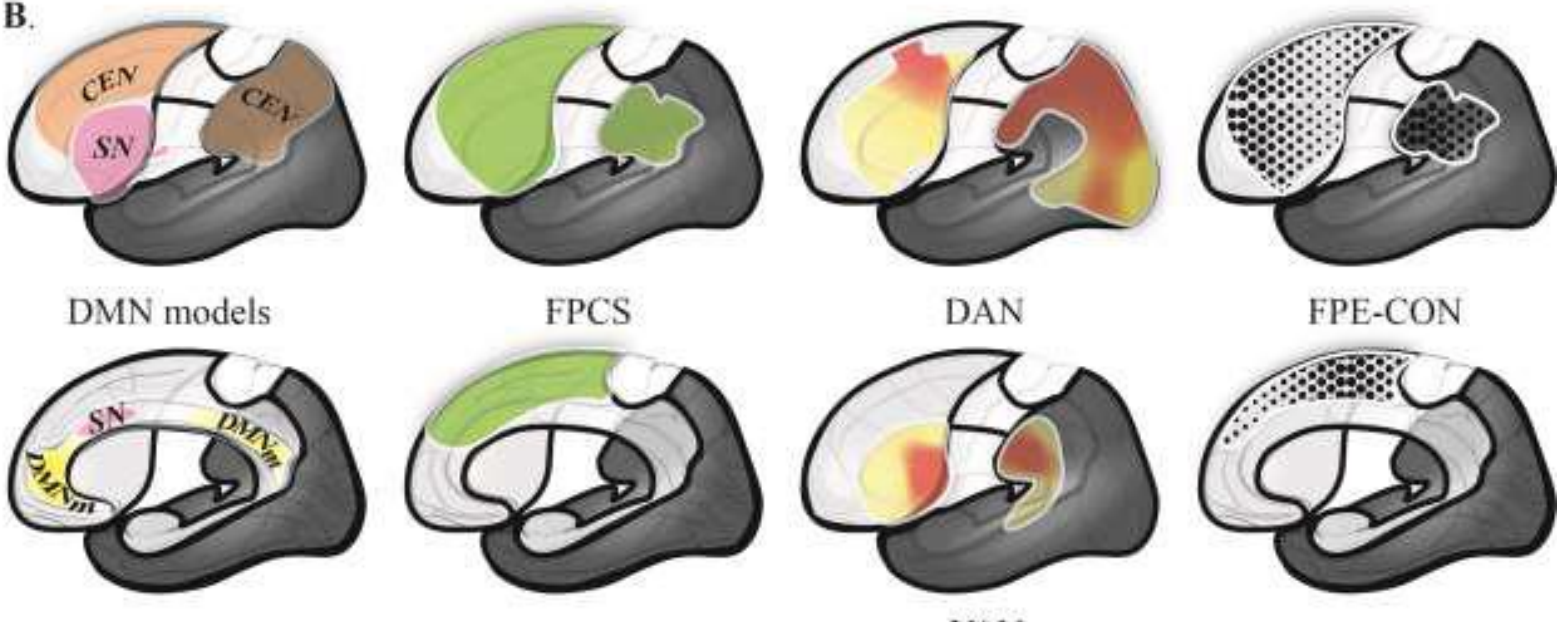

VAN

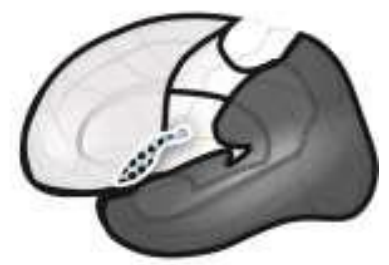

CO-SAL

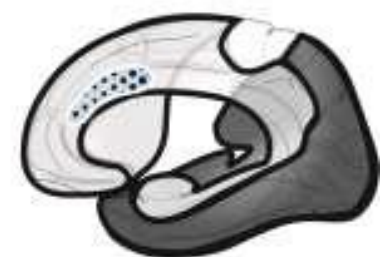

Figure 4: Cortical networks related to consciousness (see text for details). A. the historical networks: the default mode network (DMN; blue; with the medial cortices of high metabolic activity, dark blue) and the cortices that decrease their activity during goal-directed tasks (DMNdeactivation; bilaterally, red; left hemisphere, yellow; right hemisphere, green); consciousness cortices of the global workspace (Global workspace). B. Recent functional networks, from left to right: the canonical models of the DMN, the central executive (CEN, light brown), the DMN medial (DMNm, yellow) and the salience (SN, pink) networks; the 
frontoparietal control system (FPCS), which is composed notably of the dorsal attentional network (DAN) and the ventral attentional network (VAN); the frontoparietal executive control network (FPE-CON) and the cinguloopercular salient network (CO-SAL).

However, the distinction of all these functional networks, which overlap more or less depending on the methods and terminologies, still does not answer the "hard problem", sending us back to the roots of brain functioning, outside our scope here. Roughly, the dynamics of the cortical networks, notably anticorrelations, seems to be one of the most robust markers of consciousness [104,128]. One should bear in mind that these cortices also play a role in several processes or functions, up to emotion [10] and pure cognitive processes such as advanced mathematics [129].

Topological approaches of functional connectivity notably according to resting-state conditions could help to decipher the complexity of brain networks, such as graph theory [130-132], effective connectivity analysis [133], dynamics of function-structure similarities [128,134], and contextmodulated functional connectivity [135]. Even if these methods coupled with structural analysis of brains (e.g. diffusion tensor tractography) will help to decipher the pathophysiology of DOC, the complexity of lesions (figure 5) and their dynamics over time, following acute and subacute mechanisms such as ischemia, hematoma, trauma, seizure and complications of intracranial hypertension, entangle substantially the analysis of mechanisms. We should also consider that DOC stricto sensu are also truly present following progressive diseases, even if they are not fully qualified or interpreted as such, in multifactorial neurologic and psychiatric diseases, e.g. neurodegenerative diseases such as dementia whatever the context. The neural correlates of consciousness, at least from the medical viewpoint, must also consider the biology of neurotransmitters as several drugs can alleviate signs of DOC (see e.g. for a review [136], but no cross-fertilization with the data collected by studies of structural and functional dysconnectivity has yet occurred, and we do not know how these drugs act.

\section{CONCLUSION-PERSPECTIVE}

The tremendous growth of knowledge collected on consciousness over recent decades contrasts with the still limited therapeutic breakthroughs achieved, and, consequently, still very limited benefits for patients. However, it is important to disseminate and to share knowledge (including the untold stories), even if it is often inconclusive. One can reasonably hypothesize that pertinent avenues of research will soon be proposed to improve the condition of DOC patients. Nonetheless, one of the most complex issues could very likely be our capacity of deciphering the segregation and the potential hierarchization of the so-called superior functions and their related behaviors, while accounting for the neural correlates. That being so, pragmatically, the "hard medical problem" could still be patients with a high lesion burden, thus the most fragile, for whom consciousness disorder is one aspect of brain dysfunction, and for whom the hope of qualitative recovery, yet to be defined, must be discussed by taking account of the societal context. 
A.
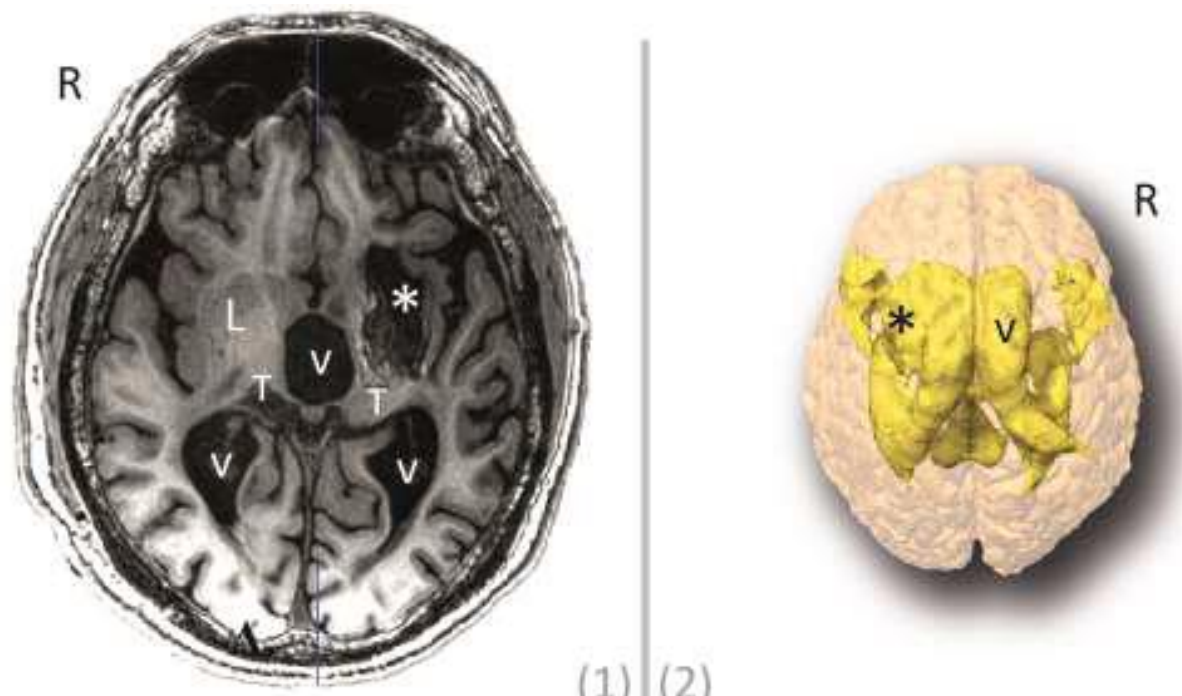

(1) (2)

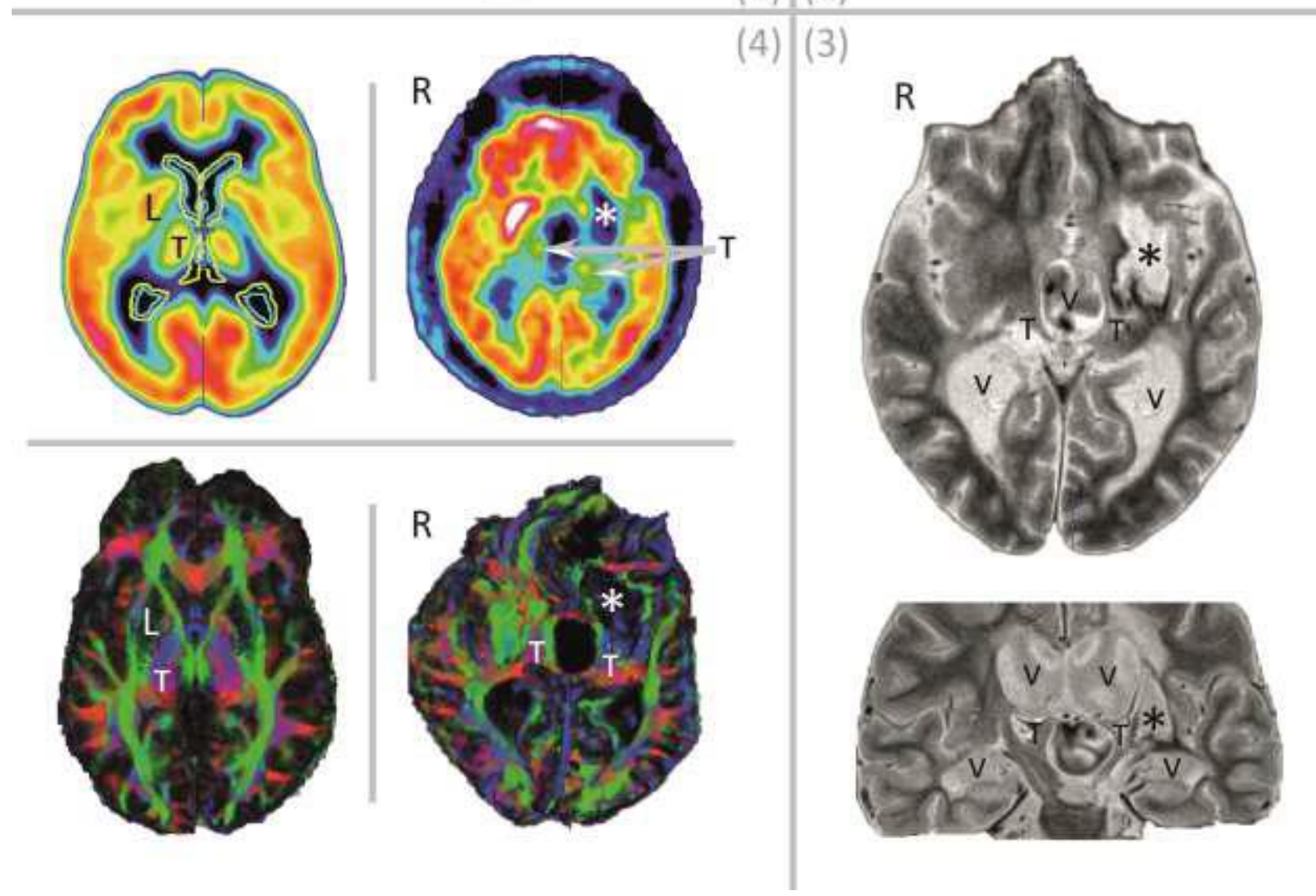



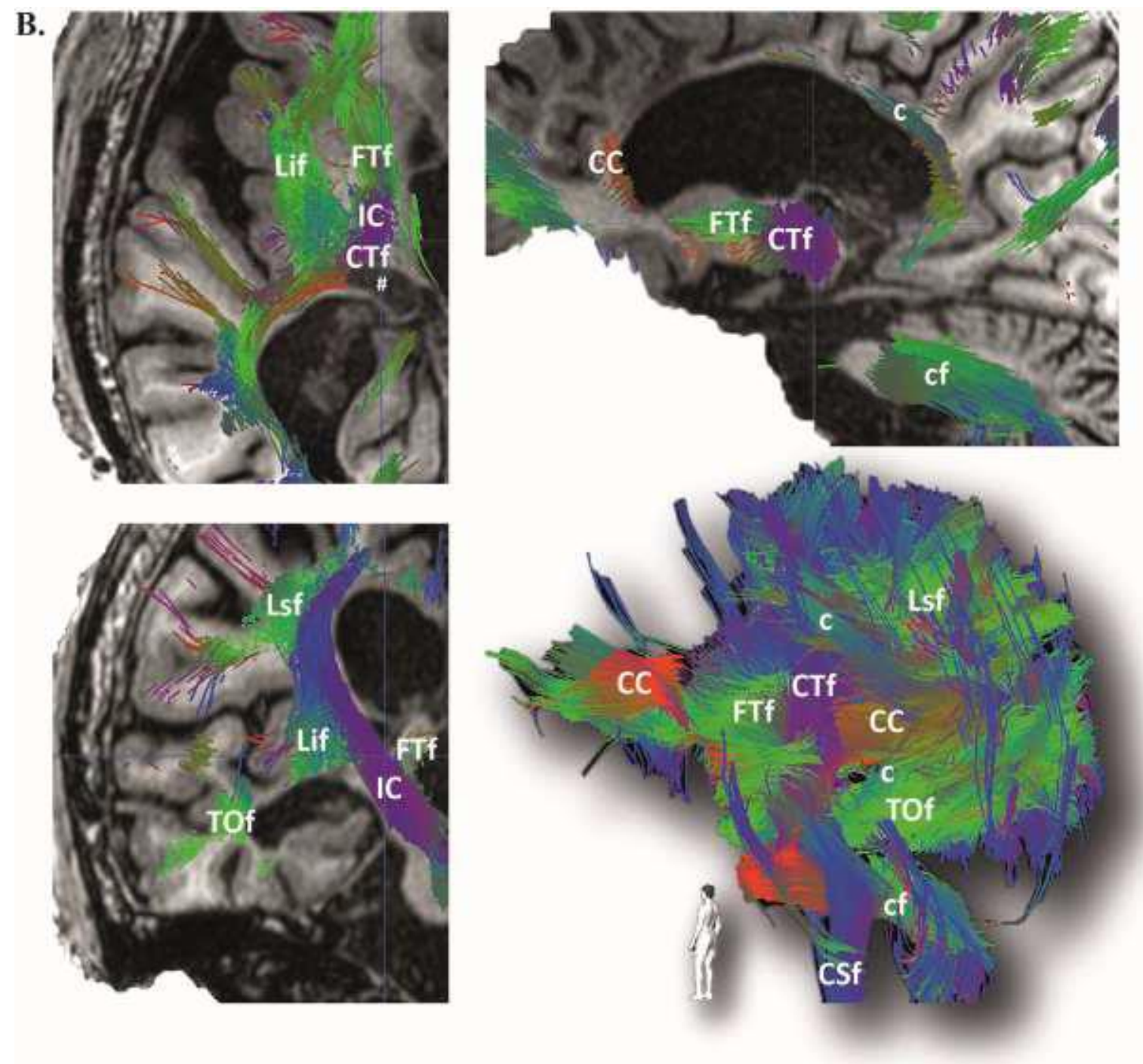

Figure 5: Image data sets and tractogram of a 32-year-old male in a vegetative state (tracheostomy, gastrostomy and ventriculoperitoneal shunt) since twelve years following a traumatic head injury, and showing complex severe subcortical lesions that predominate in the left insular and lenticular regions: A, Image data sets, (1) axial T1-weighted MRI slice, (2) 3D volumetric display of the brain (beige) and cerebrospinal fluid spaces (yellow), (3) axial (top) and coronal (bottom) inversion-recovery MRI slices, (4) axial FDG TEP-scan (top) and colorcoded diffusion tensor imaging (DTI, 20 directions bottom) slices [right row patient data; left row, top, average FDG TEPScan at rest (healthy subjects), bottom, healthy control, male, right handed, 60 directions], $R$, right hemisphere, $L$, lenticular nucleus, $V$, ventricle, $T$, thalamus, destructed left lenticular region*; B, Tractogram (DTI tractography, 20 directions), crosssections along MRI slices (top left, axial; top right, sagittal; bottom left, coronal) and posteromedial view of the $3 D$ tractogram (bottom right) of the right hemisphere showing the complexity of the disorganization of fiber bundles, notably cortico-thalamic (CTf and FTf) around the lesioned thalamus (\#), and of the cingulum; CC, corpus callosum, c, cingulum, Lsf, longitudinal superior fascicle, Lif, longitudinal inferior fascicle, IC, internal capsule, TOf, temporooccipital fascicle, CTf, cortico-thalamic fascicle, CSF, corticospinal fascicle, FTf, frontothalamic fascicle, $c f$, cerebellar fascicles. 


\section{REFERENCES}

[1] Graziano MSA. Opinion | Are We Really Conscious? The New York Times 2014.

[2] Hirsch E. Vincent Lambert - Une mort exemplaire ? Paris: Cerf; 2020.

[3] Kaiser CB. Science-Fostering Belief-Then and Now. American Scientific Association 2007;59:171-81.

[4] Dehaene S, Changeux J-P. Experimental and theoretical approaches to conscious processing. Neuron 2011;70:200-27. https://doi.org/10.1016/j.neuron.2011.03.018.

[5] De Ajuriaguerra J, Hécan H. Le cortex cérébral: étude neuro-pshycho-pathologique. Paris: Masson et Cie; 1949.

[6] Cubelli R. Definition: Apraxia. Cortex 2017;93:227. https://doi.org/10.1016/j.cortex.2017.03.012.

[7] Kumar A, Wroten M. Agnosia. StatPearls, Treasure Island (FL): StatPearls Publishing; 2020.

[8] Petreska B, Adriani M, Blanke O, Billard AG. Apraxia: a review. Progress in Brain Research, vol. 164, Elsevier; 2007, p. 61-83. https://doi.org/10.1016/S0079- 6123(07)64004-7.

[9] Karapanagiotidis T, Bernhardt BC, Jefferies E, Smallwood J. Tracking thoughts: Exploring the neural architecture of mental time travel during mind-wandering. NeuroImage 2017;147:272-81. https://doi.org/10.1016/j.neuroimage.2016.12.031.

[10] Rosenbaum D, Kroczek AM, Hudak J, Rubel J, Maier MJ, Sorg T, et al. Neural correlates of mindful emotion regulation in high and low ruminators. Sci Rep 2020;10. https://doi.org/10.1038/s41598-020-71952-5.

[11] Goldmann Gross R, Grossman M. Update on Apraxia. Curr Neurol Neurosci Rep 2008;8:490-6.

[12] Dieterich M, Kirsch V, Brandt T. Right-sided dominance of the bilateral vestibular system in the upper brainstem and thalamus. J Neurol 2017;264:55-62. https://doi.org/10.1007/s00415-017-8453-8.

[13] McAssey M, Dowsett J, Kirsch V, Brandt T, Dieterich M. Different EEG brain activity in right and left handers during visually induced self-motion perception. J Neurol 2020;267:79-90. https://doi.org/10.1007/s00415-020-09915-z.

[14] Dictionnaire de français Larrouse. 2018.

[15] Merriam-Webster dictionnary. 2020.

[16] Oxford Dictionnary of English. 2020.

[17] Quicherat L, Daveluy A. Dictionnaire LATIN-FRANCAIS. 46ème, par Emile Chatelain. Paris: Hachette et Cie; 1910.

[18] Hugo V. La Légende des siècles: la conscience". vol. 1. Hetzel. Paris, France: 1859.

[19] Barinaga M. Buddhism and neuroscience. Studying the well-trained mind. Science 2003;302:446. https://doi.org/10.1126/science.302.5642.44.

[20] Plum F, Posner J. The diagnosis of stupor and coma. 3rd ed. Philadelphia: F. A. Davis Company; 1980.

[21] Descartes R. Discours de la méthode. Leyde, Netherlands: Ian Maire; 1637.

[22] Fulton JF. Physiology of the nervous system. Oxford University Press. London, New York, Toronto: 1943.

[23] Dehaene S, Changeux J-P, Naccache L, Sackur J, Sergent C. Conscious, preconscious, and subliminal processing: a testable taxonomy. Trends Cogn Sci (Regul Ed) 2006;10:204-11. https://doi.org/10.1016/j.tics.2006.03.007.

[24] Luria AR. Higher Cortical Functions in Man. Springer Science \& Business Media; 2012.

[25] Eusop-Roussel E, Rhein F, Vassel P, Colliot P. Évaluation des fonctions supérieures. EMC Kinésithérapie - Médecine physique - Réadaptation 2006;2:1-18. https://doi.org/10.1016/S12830887(06)43871-8.

[26] Van Gulick R. Consciousness. In: Zalta EN, editor. The Stanford Encyclopedia of Philosophy. Winter 2016, Metaphysics Research Lab, Stanford University; 2016.

[27] Brown R. Consciousness doesn't overflow cognition. Front Psychol 2014;5:1399. https://doi.org/10.3389/fpsyg.2014.01399.

[28] Chalmers DJ. The Puzzle of Conscious Experience. Sci Am 1995;273:80-6. https://doi.org/10.1038/scientificamerican1295-80. 
[29] Fabbro F, Aglioti SM, Bergamasco M, Clarici A, Panksepp J. Evolutionary aspects of selfand world consciousness in vertebrates. Front Hum Neurosci 2015;9:157. https://doi.org/10.3389/fnhum.2015.00157.

[30] Vandekerckhove M, Panksepp J. The flow of anoetic to noetic and autonoetic consciousness: A vision of unknowing (anoetic) and knowing (noetic) consciousness in the remembrance of things past and imagined futures. Consciousness and Cognition 2009;18:1018-28. https://doi.org/10.1016/j.concog.2009.08.002.

[31] Martin-Ordas G, Schumacher L, Call J. Sequential tool use in great apes. PLoS ONE 2012;7:e52074. https://doi.org/10.1371/journal.pone.0052074.

[32] Wimpenny JH, Weir AAS, Clayton L, Rutz C, Kacelnik A. Cognitive processes associated with sequential tool use in New Caledonian crows. PLoS ONE 2009;4:e6471. https://doi.org/10.1371/journal.pone.0006471.

[33] Bourgine P, Stewart J. Autopoiesis and cognition. Artif Life 2004;10:327-45. https://doi.org/10.1162/1064546041255557.

[34] Wiltgen BJ, Tanaka KZ. Systems consolidation and the content of memory. Neurobiology of Learning and Memory 2013;106:365-71. https://doi.org/10.1016/j.nlm.2013.06.001.

[35] Tang C, Herikstad R, Parthasarathy A, Libedinsky C, Yen S-C. Minimally dependent activity subspaces for working memory and motor preparation in the lateral prefrontal cortex. ELife 2020;9. https://doi.org/10.7554/eLife.58154.

[36] Masse NY, Yang GR, Song HF, Wang X-J, Freedman DJ. Circuit mechanisms for the maintenance and manipulation of information in working memory. Nat Neurosci 2019;22:1159-67. https://doi.org/10.1038/s41593-019-0414-3.

[37] Matsuo N. Irreplaceability of Neuronal Ensembles after Memory Allocation. Cell Reports 2015;11:351-7. https://doi.org/10.1016/j.celrep.2015.03.042.

[38] Ramirez S, Liu X, Lin P-A, Suh J, Pignatelli M, Redondo RL, et al. Creating a False Memory in the Hippocampus. Science 2013;341:387-91. https://doi.org/10.1126/science.1239073.

[39] Winkelman M. The Evolution of Consciousness? Transpersonal Theories in Light of Cultural Relativism. Anthropology of Consciousness 1993;4:3-9. https://doi.org/10.1525/ac.1993.4.3.3.

[40] Laureys S, Celesia GG, Cohadon F, Lavrijsen J, León-Carrión J, Sannita WG, et al. Unresponsive wakefulness syndrome: a new name for the vegetative state or apallic syndrome. BMC Med 2010;8:68. https://doi.org/10.1186/1741-7015-8-68.

[41] Giacino JT, Ashwal S, Childs N, Cranford R, Jennett B, Katz DI, et al. The minimally conscious state: definition and diagnostic criteria. Neurology 2002;58:349-53.

[42] Bruno M-A, Vanhaudenhuyse A, Thibaut A, Moonen G, Laureys S. From unresponsive wakefulness to minimally conscious PLUS and functional locked-in syndromes: recent advances in our understanding of disorders of consciousness. J Neurol 2011;258:1373-84. https://doi.org/10.1007/s00415-011-6114-x.

[43] Royal College of Physicians. Prolonged disorders of consciousness following sudden onset brain injury. London: 2020.

[44] Laureys S, Schiff ND. Coma and consciousness: paradigms (re)framed by neuroimaging. Neuroimage 2012;61:478-91. https://doi.org/10.1016/j.neuroimage.2011.12.041.

[45] Fernández-Espejo D, Rossit S, Owen AM. A Thalamocortical Mechanism for the Absence of Overt Motor Behavior in Covertly Aware Patients. JAMA Neurol 2015;72:1442. https://doi.org/10.1001/jamaneurol.2015.2614.

[46] Schiff ND. Cognitive Motor Dissociation Following Severe Brain Injuries. JAMA Neurol 2015;72:1413. https://doi.org/10.1001/jamaneurol.2015.2899.

[47] Sontheimer A, Vassal F, Jean B, Feschet F, Lubrano V, Lemaire J-J. fMRI study of graduated emotional charge for detection of covert activity using passive listening to narratives. Neuroscience 2017;349:291-302. https://doi.org/10.1016/j.neuroscience.2017.02.048.

[48] Naccache L. Minimally conscious state or cortically mediated state? Brain 2018;141:949-60. https://doi.org/10.1093/brain/awx324.

[49] MacDonald AA, Naci L, MacDonald PA, Owen AM. Anesthesia and neuroimaging: investigating the neural correlates of unconsciousness. Trends Cogn Sci (Regul Ed) 2015;19:100-7. https://doi.org/10.1016/j.tics.2014.12.005.

[50] Bailly MA. Dictionnaire Grec - Français. BAILLY 2020-HUGO CHÁVEZ. Paris: 2020. 
[51] Moruzzi G, Magoun HW. Brain stem reticular formation and activation of the EEG. Electroencephalogr Clin Neurophysiol 1949;1:455-73.

[52] Lemaire J-J, Sontheimer A, Coll G, Sarret C, Nezzar H, Rosenberg S, et al. The Brainstem and Cerebral Activation. In: Lalonde R, editor. The brainstem and behavior, New York, NY: Nova Biomedical; 2017, p. 21-40.

[53] Duret RL. [A rare and little known hemorrhagic syndrome]. Brux Med 1955;35:797-800.

[54] McLardy T, Ervin F, Mark V, Scoville W, Sweet W. Attempted inset-electrodes-arousal from traumatic coma: neuropathological findings. Trans Am Neurol Assoc 1968;93:25-30.

[55] Tsubokawa T, Yamamoto T, Katayama Y, Hirayama T, Maejima S, Moriya T. Deep-brain stimulation in a persistent vegetative state: follow-up results and criteria for selection of candidates. Brain Inj 1990;4:315-27.

[56] Corazzol M, Lio G, Lefevre A, Deiana G, Tell L, André-Obadia N, et al. Restoring consciousness with vagus nerve stimulation. Current Biology 2017;27:R994-6. https://doi.org/10.1016/j.cub.2017.07.060.

[57] Llinas RR, Leznik E, Urbano FJ. Temporal binding via cortical coincidence detection of specific and nonspecific thalamocortical inputs: a voltage-dependent dye-imaging study in mouse brain slices. Proc Natl Acad Sci USA 2002;99:449-54. https://doi.org/10.1073/pnas.012604899.

[58] Van der Werf YD, Witter MP, Groenewegen HJ. The intralaminar and midline nuclei of the thalamus. Anatomical and functional evidence for participation in processes of arousal and awareness. Brain Res Brain Res Rev 2002;39:107-40.

[59] Vertes RP, Linley SB, Hoover WB. Limbic circuitry of the midline thalamus. Neurosci Biobehav Rev 2015;54:89-107. https://doi.org/10.1016/j.neubiorev.2015.01.014.

[60] Jones EG. Viewpoint: the core and matrix of thalamic organization. Neuroscience 1998;85:33145.

[61] Münkle MC, Waldvogel HJ, Faull RL. The distribution of calbindin, calretinin and parvalbumin immunoreactivity in the human thalamus. J Chem Neuroanat 2000;19:155-73.

[62] Schiff ND. Central thalamic contributions to arousal regulation and neurological disorders of consciousness. Ann N Y Acad Sci 2008;1129:105-18. https://doi.org/10.1196/annals.1417.029.

[63] Min B-K. A thalamic reticular networking model of consciousness. Theor Biol Med Model 2010;7:10. https://doi.org/10.1186/1742-4682-7-10.

[64] Pinault D. The thalamic reticular nucleus: structure, function and concept. Brain Res Brain Res Rev 2004;46:1-31. https://doi.org/10.1016/j.brainresrev.2004.04.008.

[65] Steriade M, Paré D, Parent A, Smith Y. Projections of cholinergic and non-cholinergic neurons of the brainstem core to relay and associational thalamic nuclei in the cat and macaque monkey. Neuroscience 1988;25:47-67. https://doi.org/10.1016/0306-4522(88)90006-1.

[66] Steriade M, Parent A, Paré D, Smith Y. Cholinergic and non-cholinergic neurons of cat basal forebrain project to reticular and mediodorsal thalamic nuclei. Brain Research 1987;408:372-6. https://doi.org/10.1016/0006-8993(87)90408-2.

[67] Haber SN. The primate basal ganglia: parallel and integrative networks. J Chem Neuroanat 2003;26:317-30.

[68] Haber SN, Calzavara R. The cortico-basal ganglia integrative network: the role of the thalamus. Brain Res Bull 2009;78:69-74. https://doi.org/10.1016/j.brainresbull.2008.09.013.

[69] Halassa MM, Sherman SM. Thalamo-cortical circuit motifs: a general framework. Neuron 2019;103:762-70. https://doi.org/10.1016/j.neuron.2019.06.005.

[70] Hassler R, Ore GD, Dieckmann G, Bricolo A, Dolce G. Behavioural and EEG arousal induced by stimulation of unspecific projection systems in a patient with post-traumatic apallic syndrome. Electroencephalogr Clin Neurophysiol 1969;27:306-10.

[71] Cohadon F, Richer E, Rougier A, Deliac P, Loiseau H. Deep Brain Stimulation in Cases of Prolonged Post-Traumatic Unconsciousness. Neurostimulation: An Overview. Futura Publishing Company, Mt. Kisco, New York: Lazorthes Y, Upton A.R.M.; 1985, p. 247-50.

[72] Cohadon F, Richer E. [Deep cerebral stimulation in patients with post-traumatic vegetative state. 25 cases]. Neurochirurgie 1993;39:281-92.

[73] Lemaire J, Sontheimer A, Pereira B, Coste J, Rosenberg S, Sarret C, et al. Deep brain stimulation in five patients with severe disorders of consciousness. Ann Clin Transl Neurol 2018;5:1372-84. https://doi.org/10.1002/acn3.648. 
[74] Schiff ND, Giacino JT, Kalmar K, Victor JD, Baker K, Gerber M, et al. Behavioural improvements with thalamic stimulation after severe traumatic brain injury. Nature 2007;448:600-3. https://doi.org/10.1038/nature06041.

[75] Yamamoto T, Katayama Y, Kobayashi K, Oshima H, Fukaya C, Tsubokawa T. Deep brain stimulation for the treatment of vegetative state. Eur $\mathbf{J}$ Neurosci 2010;32:1145-51. https://doi.org/10.1111/j.1460-9568.2010.07412.x.

[76] Laureys S, Faymonville ME, Luxen A, Lamy M, Franck G, Maquet P. Restoration of thalamocortical connectivity after recovery from persistent vegetative state. Lancet 2000;355:1790-1.

[77] Crick FC, Koch C. What is the function of the claustrum? Philos Trans R Soc Lond, B, Biol Sci 2005;360:1271-9. https://doi.org/10.1098/rstb.2005.1661.

[78] Critchley HD, Wiens S, Rotshtein P, Ohman A, Dolan RJ. Neural systems supporting interoceptive awareness. Nat Neurosci 2004;7:189-95. https://doi.org/10.1038/nn1176.

[79] Koubeissi MZ, Bartolomei F, Beltagy A, Picard F. Electrical stimulation of a small brain area reversibly disrupts consciousness. Epilepsy Behav 2014;37C:32-5. https://doi.org/10.1016/j.yebeh.2014.05.027.

[80] Taylor KS, Seminowicz DA, Davis KD. Two systems of resting state connectivity between the insula and cingulate cortex. Hum Brain Mapp 2009;30:2731-45. https://doi.org/10.1002/hbm.20705.

[81] Menon V, Uddin LQ. Saliency, switching, attention and control: a network model of insula function. Brain Struct Funct 2010;214:655-67. https://doi.org/10.1007/s00429-010-0262-0.

[82] Dieckmann G. Cortical synchronized and desynchronized responses evoked by stimulation of the putamen and pallidum in cats. Journal of the Neurological Sciences 1968;7:385-91. https://doi.org/10.1016/0022-510X(68)90157-3.

[83] Haber SN. Corticostriatal circuitry. Dialogues in Clinical Neuroscience 2016;18:7-21.

[84] Lemaire J-J. Related Circuitry and Synaptic Connectivity in Psychiatric Disorders. Neurosurgical Treatments for Psychiatric Disorders. Springer Netherlands, Dordrecht: Bomin Sun, Antonio De Salles; 2015, p. 1-19.

[85] Giacino JT, Fins JJ, Laureys S, Schiff ND. Disorders of consciousness after acquired brain injury: the state of the science. Nat Rev Neurol 2014;10:99-114. https://doi.org/10.1038/nrneurol.2013.279.

[86] Schiff ND. Recovery of consciousness after brain injury: a mesocircuit hypothesis. Trends Neurosci 2010;33:1-9. https://doi.org/10.1016/j.tins.2009.11.002.

[87] Crone JS, Lutkenhoff ES, Bio BJ, Laureys S, Monti MM. Testing Proposed Neuronal Models of Effective Connectivity Within the Cortico-basal Ganglia-thalamo-cortical Loop During Loss of Consciousness. Cereb Cortex 2017;27:2727-38. https://doi.org/10.1093/cercor/bhw112.

[88] Lutkenhoff ES, Chiang J, Tshibanda L, Kamau E, Kirsch M, Pickard JD, et al. Thalamic and extrathalamic mechanisms of consciousness after severe brain injury. Ann Neurol 2015;78:68-76. https://doi.org/10.1002/ana.24423.

[89] Moll CKE, Sharott A, Hamel W, Münchau A, Buhmann C, Hidding U, et al. Waking up the brain: a case study of stimulation-induced wakeful unawareness during anaesthesia. Prog Brain Res 2009;177:125-45. https://doi.org/10.1016/S0079-6123(09)17710-5.

[90] Monti MM, Lutkenhoff ES, Rubinov M, Boveroux P, Vanhaudenhuyse A, Gosseries O, et al. Dynamic Change of Global and Local Information Processing in Propofol-Induced Loss and Recovery of Consciousness. PLoS Comput Biol 2013;9. https://doi.org/10.1371/journal.pcbi.1003271.

[91] Di Perri C, Stender J, Laureys S, Gosseries O. Functional neuroanatomy of disorders of consciousness. Epilepsy Behav 2014;30:28-32. https://doi.org/10.1016/j.yebeh.2013.09.014.

[92] Duffau H, Denvil D, Capelle L. Absence of movement disorders after surgical resection of glioma invading the right striatum. J Neurosurg 2002;97:363-9. https://doi.org/10.3171/jns.2002.97.2.0363.

[93] Fukuoka T, Osawa A, Ohe Y, Deguchi I, Maeshima S, Tanahashi N. Bilateral caudate nucleus infarction associated with a missing A1 segment. J Stroke Cerebrovasc Dis 2012;21:908.e11-12. https://doi.org/10.1016/j.jstrokecerebrovasdis.2011.09.022.

[94] Jain SK, Sundar IV, Sharma V, Prasanna KL, Kulwal G, Tiwari RN. Bilateral large traumatic basal ganglia haemorrhage in a conscious adult: a rare case report. Brain Inj 2013;27:500-3. https://doi.org/10.3109/02699052.2013.765597.

[95] Baars BJ. Global workspace theory of consciousness: toward a cognitive neuroscience of human experience. Prog Brain Res 2005;150:45-53. https://doi.org/10.1016/S0079-6123(05)50004-9. 
[96] Baars BJ. A Cognitive Theory of Consciousness. Cambridge University Press. Cambridge, New York, USA; Melbourne Australia: Press Syndicate of the University of Cambridge; 1988.

[97] Dehaene S, Kerszberg M, Changeux JP. A neuronal model of a global workspace in effortful cognitive tasks. Proc Natl Acad Sci USA 1998;95:14529-34.

[98] Newman J, Baars BJ, Cho S-B. A Neural Global Workspace Model for Conscious Attention. Neural Networks 1997;10:1195-206. https://doi.org/10.1016/S0893-6080(97)00060-9.

[99] Aru J, Suzuki M, Rutiku R, Larkum ME, Bachmann T. Coupling the State and Contents of Consciousness. Front Syst Neurosci 2019;13:43. https://doi.org/10.3389/fnsys.2019.00043.

[100] Crick F, Koch C. A framework for consciousness. Nat Neurosci 2003;6:119-26. https://doi.org/10.1038/nn0203-119.

[101] Raffone A, Pantani M. A global workspace model for phenomenal and access consciousness. Conscious Cogn 2010;19:580-96. https://doi.org/10.1016/j.concog.2010.03.013.

[102] Aleman B, Merker B. Consciousness without cortex: a hydranencephaly family survey. Acta Paediatr 2014;103:1057-65. https://doi.org/10.1111/apa.12718.

[103] Raichle ME, MacLeod AM, Snyder AZ, Powers WJ, Gusnard DA, Shulman GL. A default mode of brain function. Proc Natl Acad Sci USA 2001;98:676-82. https://doi.org/10.1073/pnas.98.2.676.

[104] Shulman GL, Fiez JA, Corbetta M, Buckner RL, Miezin FM, Raichle ME, et al. Common Blood Flow Changes across Visual Tasks: II. Decreases in Cerebral Cortex. Journal of Cognitive Neuroscience 1997;9:648-63. https://doi.org/10.1162/jocn.1997.9.5.648.

[105] Boveroux P, Vanhaudenhuyse A, Bruno M-A, Noirhomme Q, Lauwick S, Luxen A, et al. Breakdown of within- and between-network Resting State Functional Magnetic Resonance Imaging Connectivity during Propofol-induced Loss of Consciousness. Anesthesiology 2010. https://doi.org/10.1097/ALN.0b013e3181f697f5.

[106] Buckner RL, Andrews-Hanna JR, Schacter DL. The brain's default network: anatomy, function, and relevance to disease. Ann N Y Acad Sci 2008;1124:1-38. https://doi.org/10.1196/annals.1440.011.

[107] Corbetta M, Shulman GL. Spatial neglect and attention networks. Annu Rev Neurosci 2011;34:569-99. https://doi.org/10.1146/annurev-neuro-061010-113731.

[108] Corbetta M, Shulman GL. Control of goal-directed and stimulus-driven attention in the brain. Nat Rev Neurosci 2002;3:201-15. https://doi.org/10.1038/nrn755.

[109] Dang LC, O’Neil JP, Jagust WJ. Dopamine supports coupling of attention-related networks. J Neurosci 2012;32:9582-7. https://doi.org/10.1523/JNEUROSCI.0909-

12.2012 .

[110] Vanhaudenhuyse A, Noirhomme Q, Tshibanda LJ-F, Bruno M-A, Boveroux P, Schnakers C, et al. Default network connectivity reflects the level of consciousness in noncommunicative braindamaged patients. Brain 2010;133:161-71. https://doi.org/10.1093/brain/awp313.

[111] Gusnard DA, Raichle ME, Raichle ME. Searching for a baseline: functional imaging and the resting human brain. Nat Rev Neurosci 2001;2:685-94. https://doi.org/10.1038/35094500.

[112] Leech R, Sharp DJ. The role of the posterior cingulate cortex in cognition and disease. Brain 2014;137:12-32. https://doi.org/10.1093/brain/awt162.

[113] Fox MD, Snyder AZ, Vincent JL, Corbetta M, Van Essen DC, Raichle ME. The human brain is intrinsically organized into dynamic, anticorrelated functional networks. Proc Natl Acad Sci USA 2005;102:9673-8. https://doi.org/10.1073/pnas.0504136102.

[114] Hannawi Y, Lindquist MA, Caffo BS, Sair HI, Stevens RD. Resting brain activity in disorders of consciousness: a systematic review and meta-analysis. Neurology 2015;84:1272-80. https://doi.org/10.1212/WNL.0000000000001404.

[115] Silva S, de Pasquale F, Vuillaume C, Riu B, Loubinoux I, Geeraerts T, et al. Disruption of posteromedial large-scale neural communication predicts recovery from coma. Neurology 2015;85:2036-44. https://doi.org/10.1212/WNL.0000000000002196.

[116] Seeley WW, Menon V, Schatzberg AF, Keller J, Glover GH, Kenna H, et al. Dissociable intrinsic connectivity networks for salience processing and executive control. J Neurosci 2007;27:2349-56. https://doi.org/10.1523/JNEUROSCI.5587-06.2007.

[117] Sridharan D, Levitin D, Menon V. A critical role for the right fronto-insular cortex in switching between central-executive and default-mode networks. Proceedings of the National Academy of Sciences of the United States of America 2008;105. https://doi.org/10.1073/pnas.0800005105. 
[118] Gao W, Lin W. Frontal parietal control network regulates the anti-correlated default and dorsal attention networks. Human Brain Mapping 2012;33:192-202. https://doi.org/10.1002/hbm.21204.

[119] Spreng RN, Sepulcre J, Turner GR, Stevens WD, Schacter DL. Intrinsic Architecture Underlying the Relations among the Default, Dorsal Attention, and Frontoparietal Control Networks of the Human Brain. Journal of Cognitive Neuroscience 2012;25:74-86. https://doi.org/10.1162/jocn_a_00281.

[120] Elton A, Gao W. Divergent task-dependent functional connectivity of executive control and salience networks. Cortex 2014;51:56-66. https://doi.org/10.1016/j.cortex.2013.10.012.

[121] Bruno M-A, Majerus S, Boly M, Vanhaudenhuyse A, Schnakers C, Gosseries O, et al. Functional neuroanatomy underlying the clinical subcategorization of minimally conscious state patients. J Neurol 2012;259:1087-98. https://doi.org/10.1007/s00415-011-6303-7.

[122] Stender J, Gosseries O, Bruno M-A, Charland-Verville V, Vanhaudenhuyse A, Demertzi A, et al. Diagnostic precision of PET imaging and functional MRI in disorders of consciousness: a clinical validation study. Lancet 2014;384:514-22. https://doi.org/10.1016/S0140-6736(14)60042-8.

[123] Hermann B, Raimondo F, Hirsch L, Huang Y, Denis-Valente M, Pérez P, et al. Combined behavioral and electrophysiological evidence for a direct cortical effect of prefrontal tDCS on disorders of consciousness. Sci Rep 2020;10:4323. https://doi.org/10.1038/s41598-020-61180-2.

[124] Thibaut A, Di Perri C, Chatelle C, Bruno M-A, Bahri MA, Wannez S, et al. Clinical Response to tDCS Depends on Residual Brain Metabolism and Grey Matter Integrity in Patients With Minimally Conscious State. Brain Stimul 2015;8:1116-23. https://doi.org/10.1016/j.brs.2015.07.024.

[125] Boly M, Phillips C, Balteau E, Schnakers C, Degueldre C, Moonen G, et al. Consciousness and cerebral baseline activity fluctuations. Hum Brain Mapp 2008;29:868-74. https://doi.org/10.1002/hbm.20602.

[126] Thibaut A, Bruno M-A, Chatelle C, Gosseries O, Vanhaudenhuyse A, Demertzi A, et al. Metabolic activity in external and internal awareness networks in severely brain-damaged patients. J Rehabil Med 2012;44:487-94. https://doi.org/10.2340/16501977-0940.

[127] Vanhaudenhuyse A, Demertzi A, Schabus M, Noirhomme Q, Bredart S, Boly M, et al. Two distinct neuronal networks mediate the awareness of environment and of self. J Cogn Neurosci 2011;23:570-8. https://doi.org/10.1162/jocn.2010.21488.

[128] Barttfeld P, Uhrig L, Sitt JD, Sigman M, Jarraya B, Dehaene S. Signature of consciousness in the dynamics of resting-state brain activity. Proc Natl Acad Sci USA 2015;112:887-92. https://doi.org/10.1073/pnas.1418031112.

[129] Amalric M, Dehaene S. Origins of the brain networks for advanced mathematics in expert mathematicians. Proc Natl Acad Sci USA 2016. https://doi.org/10.1073/pnas.1603205113.

[130] Achard S, Delon-Martin C, Vertes PE, Renard F, Schenck M, Schneider F, et al. Hubs of brain functional networks are radically reorganized in comatose patients. Proceedings of the National Academy of Sciences 2012;109:20608-13. https://doi.org/10.1073/pnas.1208933109.

[131] Bullmore E, Sporns O. Complex brain networks: graph theoretical analysis of structural and functional systems. Nat Rev Neurosci 2009;10:186-98. https://doi.org/10.1038/nrn2575.

[132] Hagmann P, Cammoun L, Gigandet X, Meuli R, Honey CJ, Wedeen VJ, et al. Mapping the structural core of human cerebral cortex. PLoS Biol 2008;6:e159. https://doi.org/10.1371/journal.pbio.0060159.

[133] Friston KJ. Functional and Effective Connectivity: A Review. Brain Connectivity 2011;1:13-36. https://doi.org/10.1089/brain.2011.0008.

[134] Uhrig L, Sitt JD, Jacob A, Tasserie J, Barttfeld P, Dupont M, et al. Resting-state Dynamics as a Cortical Signature of Anesthesia in Monkeys. Anesthesiology 2018;129:942-58. https://doi.org/10.1097/ALN.0000000000002336.

[135] Cisler JM, Bush K, Steele JS. A Comparison of Statistical Methods for Detecting ContextModulated Functional Connectivity in fMRI. Neuroimage 2014;84:1042-52. https://doi.org/10.1016/j.neuroimage.2013.09.018.

[136] Lemaire J-J, Sontheimer A, Nezzar H, Pontier B, Luauté J, Roche B, et al. Electrical modulation of neuronal networks in brain-injured patients with disorders of consciousness: a systematic review. Ann Fr Anesth Reanim 2014;33:88-97. https://doi.org/10.1016/j.annfar.2013.11.007. 